\title{
SOURCE AND NATURE OF DISTURBANCE-CHEMICAL SYSTEM IN CRAYFISH
}

\author{
BRIAN A. HAZLETT \\ Department of Biology \\ University of Michigan \\ Ann Arbor, Michigan 48109 \\ University of Michigan Biological Station \\ Pellston, Michigan 49769
}

(Received October 31, 1989; accepted January 17, 1990)

\begin{abstract}
The responses of crayfish to water from aquaria containing either undisturbed or disturbed animals were observed. The crayfish Orconectes propinquus and $O$. rusticus showed no response to disturbed-conspecific water. Individuals of $O$. virilis respond not only to disturbed crayfish but to other taxa (the leech Macrobdella decora, the darter Etheostoma exile, and rock bass Ambloplites rupestris), but not to the painted turtle Chrsymes picta. Additional tests indicated partial responses by $O$. virilis to ammonium and to a chemical or chemicals released from the green gland of crayfish. Ablation experiments indicated the antennules as the site of reception of the chemicals. Additional behavioral tests indicated that detection of the disturbance chemical(s) results in the crayfish showing low-level alert for more than $15 \mathrm{~min}$, once an initial priming period has passed.
\end{abstract}

Key Words-Disturbance, semiochemical, communication, crayfish, Orconectes propinquus, $O$. rusticus, $O$. virilis, cross-taxa effects, pheromone, ammonium, antennules, green gland.

\section{INTRODUCTION}

Alteration of behavior upon detection of chemical signals given off by organisms belonging to different taxa is a widely recognized phenomenon in recent years. In many cases, the detection of a potential predator alters the behavior of potential prey (Petranka et al., 1987; Stemberger and Gilbert, 1987). In other cases, closely related animals may utilize each other's signals (Hazlett, 1985b), perhaps as a result of phylogenetic inertia. In the current study, the diversity of both sources and recipients of a chemical signal were investigated. 
The chemical communication system of interest is the disturbance "pheromone" of the crayfish Orconectes virilis (Hazlett, 1985a). When conspecific individuals are disturbed (made more active by any of several means) but not injured, individuals of $O$. virilis show a set of postures that are associated with low-level alert. The postures shown are intermediate between the resting postures of the crayfish and those postures associated with specific sources of danger or disturbance to the crayfish. In addition to conspecifics, individuals of other species (Hazlett, 1985b) and genera (Hazlett, 1989) of crayfish can serve as sources of the chemical. Attempts to demonstrate that animals in more distant taxa could serve as sources of the chemical were not successful (Hazlett, 1989).

In addition to looking at the diversity of sources and recipients of this chemical, the present study also looks at several aspects of the changes in behavior elicited by the perception of the pheromone. The sites of release and detection of the pheromone in crayfish were also studied.

\section{METHODS AND MATERIALS}

Experiments were conducted at the University of Michigan Biological Station, Pellston, Michigan, during July and August, 1988 and 1989. In general, methods were identical to those described earlier (Hazlett, 1985a,b, 1989). The crayfish tested (Orconectes virilis, $O$. propinquus, and $O$. rusticus) were housed individually in 10-gallon aquaria $(26 \times 51 \mathrm{~cm}$ bottom area) that were visually isolated and had a water depth of $10 \mathrm{~cm}$. Each test crayfish was provided with a clay burrow, and the water in the aquarium was fully aerated at all times. An individual was tested with just one type of water per day. Water to be tested was introduced via a peristaltic pump at the rate of $20 \mathrm{ml} / \mathrm{min}$ for a test period of $8 \mathrm{~min}$, except where noted.

The behavior patterns recorded have been described earlier (Hazlett, 1985a,b, 1989) and involved three positions (raised, neutral, lowered) of three body parts (chelipeds, cephalothorax, abdomen). All observations were done between 0800 and $1400 \mathrm{hr}$, a time of day when the crayfish are normally quiescent, resting in a fully lowered posture, usually at the entrance of their burrow. Earlier work showed that the primary response by crayfish to disturbance chemicals was the assumption of a neutral posture. In this posture the abdomen is partially extended with the uropods approximately perpendicular to the substratum, the walking legs extended partially such that the carapace is clearly not touching the substratum, and the chelipeds are partially extended with the tips of the dactyls lightly touching the substratum. The data compared in this study are the number of seconds spent by test crayfish with any body part in the neutral position when various sources of water were introduced into the aquaria via a clear plastic tube connected to a perstaltic pump. In some cases, the num- 
ber of seconds spent in the fully lowered posture also was compared. In most cases, paired $t$ tests were run to see if the responses of individual crayfish were different under different conditions. ANOVA was used to examine the results from the duration-of-effect test (see below) and unpaired $t$ tests were used for the ablation experiments.

Other Animals as Sources. Earlier studies (Hazlett, 1985b, 1989) showed that individuals of Orconectes virilis responded to disturbance chemicals from a variety of types of crayfish (conspecifics, at least two congeners, and at least one Cambarus species) as well as suggesting a response to other types of aquatic animals. To further investigate the possibility that crayfish respond to a chemical or chemicals given off by disturbed (but not injured) animals in other taxa, four aquatic species sympatric with $O$. virilis were tested as source animals. Continually aerated water from aquaria containing undisturbed or disturbed (by simulated predator chase every $30 \mathrm{sec}$ during the observation period, no physical damage inflicted) individuals was introduced to individual $O$. virilis and the postures of the crayfish recorded for $8 \mathrm{~min}$ on a PC event recorder. The source species tested were (1) 12 individuals of the darter, Etheostoma exile, (2) four large individuals of the leech, Macrobdella decora, (3) two individuals of the rock bass, Ambloplites rupestris, and (4) one individual of the painted turtle, Chrsymes picta. The rock bass was tested only in the "disturbed" situation as it was not possible to get those fish to be fully undisturbed in the laboratory.

Sources of Pheromone in Crayfish. The fact that the disturbance pheromone is given off by metabolically active crayfish suggested the possibility that the green gland could be the site of release of the pheromone. Alternatively, the fact (from above and earlier work) that all source species that elicit a response are ammonotilic and the species that did not elicit a response (painted turtle) is ureotilic suggests ammonia/ammonium ion as a possible basis of the reponse. Water samples ( $\mathrm{pH}$ 8.3) analyzed on a Techicon Autoanalyzer II showed an increase in ammonium from about $30 \mu \mathrm{g} /$ liter from aquaria with undisturbed crayfish to $250 \mu \mathrm{g} /$ liter in aquaria with disturbed crayfish. (The behavioral tests mentioned above were done in 1988, prior to the suggestion that ammonium might be involved, thus no measurements of ammonium concentration were made.)

Based upon the above, a set of individual $O$. virilis were tested with the following sequence of sources: (1) self water-as a control and to establish a baseline of behavior (see Rose, 1986, for a discussion of this type of control), (2) standard $O$. rusticus - two individuals of $O$. rusticus in about 8 liters of water were repeatedly agitated during the $8 \mathrm{~min}$ delivery/observation period, (3) ammonium-a solution of $200 \mu \mathrm{g} /$ liter ammonium chloride in filtered lake water, solutions made up daily and used within an hour after mixing, (4) plugged green gland-the orifices of the green glands of two individuals of $O$. rusticus 
were covered over with cyanoacrylate glue; these disturbed crayfish were rinsed in running lake water and placed in 4 liters of water to serve as a source of disturbance pheromone, (5) control glue-two individuals of $O$. rusticus had cyanoacrylate glue spread over portions of their carapace, were rinsed off and placed in 4 liters of water to serve as a source of disturbance pheromone. It should be noted that the primary site of ammonia release by crayfish is the gills, rather than the green gland.

Reception of Pheromone. To examine the possible site of pheromone reception, ablations were performed on 20 individuals of $O$. virilis. Ten individuals had both antennae removed, and 10 individuals had both antennules removed. All operated crayfish were allowed to recover for $48 \mathrm{hr}$ and then tested with water from disturbed individuals of $O$. rusticus.

Nature of Response by $O$. virilis. It was noted in earlier studies (Hazlett, 1985b) that there appeared to be a marked delay of about $2 \mathrm{~min}$ between the introduction of test water and any response by target crayfish. Two experiments were done to see if this delay was due to the need to exceed some threshold concentration of the pheromone in the surrounding water. In the first experiment, water from an aquarium with either (1) one disturbed $O$. rusticus or (2) five disturbed $O$. rusticus was introduced to individual $O$. virilis, and the time until a response (=change in behavioral postures) was shown was recorded. In the second experiment, water from an aquarium containing two disturbed $O$. rusticus was introduced to individual $O$. virilis at a rate of either (1) $20 \mathrm{ml} / \mathrm{min}$ or (2) $60 \mathrm{ml} / \mathrm{min}$. The latency until a response was shown was recorded.

The second type of experiment concerning the nature of the response looked at how long the behavior of recipient crayfish was modified by detection of the chemical(s). Water from two disturbed $O$. rusticus was introduced at $20 \mathrm{ml} /$ min for $6 \mathrm{~min}$. At the end of this time, water delivery stopped and data on the postures of the recipient crayfish were recorded for $15 \mathrm{~min}$. During control periods, self water was introduced and the crayfish's behavior followed for 15 min after the cessation of self-water introduction. In subsequent analyses, the data were divided into three 5-min periods and ANOVA used to test for changes in the difference of test and control situations over time.

The third type of experiment examined how perception of the disturbance chemical by individual $O$. virilis altered their responsiveness to other types of stimuli. Crayfish were exposed to either self water or water from an aquarium with disturbed $O$. rusticus for $5 \mathrm{~min}$. The crayfish then were exposed to one of two types of stimuli and the latency of response measured. The light stimulus consisted of flashes from a Thyristor electronic flash placed next to the aquarium, facing the crayfish, and discharged once every $5 \mathrm{sec}$. The food stimulus was water containing a macerated piece of fish (rock bass) delivered at the rate of $25 \mathrm{ml} / \mathrm{min}$. The food-related response to fish odor was qualitatively different from the responses shown to disturbance pheromone in terms of both the pos- 
tures assumed (chelae raised, abdomen fully extended) and the greater speed of locomotion following the food odor. Ten crayfish were tested once with each type of stimulus under primed (from delivery of disturbance-chemical water) and control conditions.

Responses of Other Species of Crayfish. To examine the generality of the responses to disturbance pheromone shown by individuals of Orconectes virilis, individuals of two other species were tested. Water was introduced at the rate of $20 \mathrm{ml} / \mathrm{min}$ for $8 \mathrm{~min}$. Specimens of $O$. propinquus were collected from the Maple River and the postures recorded as water from undisturbed and disturbed (by simulated predator chase) specimens of (1) O. propinquus and (2) O. virilis was introduced. Specimens of $O$. rusticus were collected from Burt Lake and tested with water from undisturbed and disturbed conspecific specimens.

\section{RESULTS}

The results of tests using sources of the pheromone other than crayfish are shown in Table 1. Considering the amounts of time spent in neutral and the full down positions by recipient crayfish, both the darters and the leeches clearly elicited a response on the part of $O$. virilis when they were disturbed. When the darters or leeches were disturbed, the crayfish spent more time in the neutral postures and less time in the full down posture than when water from undisturbed darters or leeches was introduced. While the response appeared to be less intense or reliable than that evoked by water from disturbed crayfish (Hazlett, 1985a), there were very significant differences in crayfish behavior depending upon the condition of the animals belonging to the other taxa. This was not true of the painted turtle. Although the data tended to vary in the same

Table 1. Average ( \pm SD) Number of Seconds during 8-Minute Observation Spent by $O$. virilis with One or More Parts in Neutral and Full Down Posture when Water from Various Sources (Sample Sizes in Parentheses) was INTRODUCED $^{a}$

\begin{tabular}{llcccccc}
\hline & \multicolumn{3}{c}{ Neutral postures } & & \multicolumn{3}{c}{ Full down posture } \\
\cline { 2 - 3 } \cline { 7 - 8 } Source water & Undisturbed & Disturbed & $P$ & & Undisturbed & Disturbed & $P$ \\
\hline Darters (19) & $98( \pm 134)$ & $170( \pm 116)$ & 0.109 & & $342( \pm 160)$ & $186( \pm 131)$ & 0.002 \\
Leeches (20) & $89( \pm 68)$ & $192( \pm 122)$ & 0.002 & & $309( \pm 150)$ & $187( \pm 136)$ & 0.001 \\
Turtle (14) & $84( \pm 91)$ & $136( \pm 112)$ & 0.157 & & $340( \pm 148)$ & $235( \pm 154)$ & 0.058 \\
Bass (19) & & $285( \pm 137)$ & & & & $138( \pm 143)$ &
\end{tabular}

\footnotetext{
${ }^{a} P$ values associated with paired $t$ test comparing responses to water from undisturbed and disturbed
} source animals. 
general way as with the other taxa, there were no significant differences in postures with disturbed and undisturbed $C$. picta.

In an earlier study (Hazlett, 1989), evidence for differential responses by crayfish to disturbed and undisturbed noncrustaceans was equivocal. In the case of the red-spotted newt (Notopthalamus viridescens), crayfish responded to disturbed-animal source water as if the water contained a toxin. There was no significant difference in responses to water from disturbed and "undisturbed" catfish (Ictalurus natalis). The latter result, in contrast to the results reported for darters and leeches in the current study, was probably due to the lack of really undisturbed source animals. While the catfish used in the earlier study seemed to settle down in the laboratory rather well, they always displayed some level of "nervous" activity. In the case of both darters and leeches (and painted turtles), the undisturbed animals were very quiescent. As noted earlier (Hazlett, 1989), unless both source and recipient animals can be observed in an undisturbed state, detection of a response to disturbed-animal water is not possible.

The responses shown to the disturbed rock bass could not be compared directly to undisturbed rock bass because these fish were sufficiently jumpy in the laboratory that obtaining water from undisturbed individuals proved very difficult. The reponses of crayfish to water from rock bass were compared with two other sources of the chemicals, the crayfish $O$. rusticus and the darters. The rock bass evoked significantly more seconds spent in the neutral postures than the disturbed darters $(t=2.88, P<0.01)$ and were not significantly different from the pattern evoked by the crayfish $O$. rusticus $(t=1.2, P>0$ .10 ). The relatively high level of response to disturbed rock bass may be associated with the fact that the fish were disturbed for several days (while in the laboratory situation) rather than just the few minutes before a set of tests.

The results of the tests on the source of the pheromone in crayfish are shown in Table 2. While a number of comparisons are possible here, the essential information derives from two comparisons for each set of data. Use of the

Table 2. Average ( \pm SD) Number of Seconds during 8-min Oservation Spent by

$O$. virilis with One or More Parts in Neutral and Full Down Posture when WATER FROM VARIOUS SOURCES WAS INTRODUCED ${ }^{a}$

\begin{tabular}{lcc}
\hline Source of water & Neutral postures & Full down posture \\
\hline Self water & $39( \pm 76)$ & $440( \pm 77)$ \\
Standard & $234( \pm 131)$ & $232( \pm 145)$ \\
Ammonia & $131( \pm 150)$ & $337( \pm 165)$ \\
Plugged green & $109( \pm 133)$ & $365( \pm 138)$ \\
Control plugged & $225( \pm 136)$ & $251( \pm 138)$ \\
\hline
\end{tabular}

${ }^{a}$ All sample sizes were 20 . 
data in two comparisons weakens the $P$ values obtained slightly, but since only two comparisons are made with each data set, the robust results obtained are not materially changed. In every case, the $t$ test values associated with comparison of neutral and full down postures yielded similar conclusions, thus just the results for the comparison of neutral postures are mentioned.

The responses shown to self water were very different from those shown to standard $O$. rusticus water $(P=0.0001)$, as in previous studies (Hazlett, 1985a). The responses shown to ammonium were significantly different from those shown to self water $(P=0.013$ ) with more time spent in neutral postures. The responses to water from animals with plugged green glands were not significantly different from the ammonia tests $(P=0.605)$, but they were significantly different from the control plugged animals $(P=0.001)$. The latter were not different from the standard disturbed $O$. rusticus tests $(P=0.989)$. Because ammonium is given from the gills in crayfish, the animals with the green gland plugged were still giving off ammonia; thus the similarity of the response to ammonia and plugged green gland conditions is to be expected. The above results strongly suggest that the disturbance chemical response is to a composite of perception of ammonia and possibly other chemicals (from the gills) and some substance or substances released from the green gland. The green gland has been identified as the source of a number of pheromones in crustacea (Gleeson, 1980, and references therein).

The results of the ablation experiments (Table 3 ) clearly indicate that the antennules are the site of detection of the chemical(s). When water from disturbed $O$. rusticus was introduced to animals with the antennae removed, the response was not different from that shown by intact animals $(P>0.05)$. The responses of the animals with antennules removed was significantly different from the responses of animals without antennae $(P<0.001)$ but was not different from responses shown to self water $(P>0.10)$. Antennuleless animals behaved as if there was no chemicals in the water.

The studies of the nature of the response to disturbance pheromone will be

Table 3. Average ( \pm SD) Number of Seconds during 8-min Observation Spent by $O$. virilis with One or More Parts in Neutral and Full Down Posture when WATER FROM DISTURBED $O$. rusticus WAS INTRODUCED ${ }^{a}$

\begin{tabular}{lcc}
\hline Part removed & Neutral postures & Full down posture \\
\hline Antennae & $343( \pm 102)$ & $102( \pm 101)$ \\
Antennules & $69( \pm 120)$ & $409( \pm 130)$ \\
None/standard & $234( \pm 131)$ & $232( \pm 145)$ \\
\hline
\end{tabular}

\footnotetext{
${ }^{a}$ The test crayfish had either antennae or antennules removed two days before the test. The responses
} shown under "standard/none" conditions are included from Table 2 for general comparison. 
considered in three parts. The first question addressed was why there is a marked delay between introduction of the chemical-containing water to an aquarium and the first responses of a recipient crayfish. Utilization of five disturbed individuals of $O$. rusticus as the source of the chemical(s) did not result in any decrease in the latency of response (mean seconds to respond were 92 and 129 for one and five source crayfish, respectively, $P=0.193$ ). When water from disturbed $O$. rusticus was introduced at a threefold higher rate, there was no difference in the latency (mean seconds to respond were 139 and 157 for pulse and normal rates, respectively, $P>0.10$ ). The results of both tests suggest that the latency is a function of some central process rather than a detection threshold.

The results of the tests to see how long the pheromone-induced changes in behavior lasted were inconclusive (Table 4) in the sense that even after 15 min without addition of source water there was no significant difference in the pattern of response compared to the response pattern right after cessation. The fact that there was neither a time effect or a time * treatment effect in the ANOVA shows that the patterns of behavior persist for at least $15 \mathrm{~min}$. Combined with the results of the test mentioned in the previous paragraph, it would appear that the behavioral response of crayfish to disturbance chemical is slow to develop but persists for some time.

The tests comparing the responses of crayfish to other types of input when primed by disturbance chemical yielded very clear results. The latency to respond to flashes of light was significantly lower when the crayfish had detected

Table 4. Average $( \pm$ SD) Number of Seconds Spent during 5-min Periods Following Cessation of Disturbance Pheromone by $O$. virilis with One or More Parts in Neutral and Full Down Posture ${ }^{a}$

\begin{tabular}{ccc}
\hline & Neutral postures & Full down posture \\
\hline First 5 min & & \\
Control & $28( \pm 67)$ & $268( \pm 77)$ \\
Disturbance & $166( \pm 124)$ & $134( \pm 125)$ \\
Second 5 min & & \\
Control & $41( \pm 71)$ & $258( \pm 71)$ \\
Disturbance & $201( \pm 93)$ & $98( \pm 93)$ \\
Third 5 min & $31( \pm 69)$ & $268( \pm 64)$ \\
Control & $112( \pm 95)$ & $178( \pm 105)$ \\
Disturbance & $P=0.509$ & $P=0.626$ \\
Time effect & $P=0.004$ & $P=0.008$ \\
Treatment effect & $P=0.325$ & $P=0.447$ \\
Time $*$ treatment & & \\
\hline
\end{tabular}

${ }^{a}$ Ten individuals followed for $15 \mathrm{~min}$ each for both test and control periods. 
disturbance chemical(s) (mean of $6.8 \mathrm{sec}$ vs. $35.5 \mathrm{sec}, P=0.038$ ). Similarly, the latency to respond to the input of chemicals associated with food was significantly shorter ( $73.3 \mathrm{vs} .115 \mathrm{sec}, P=0.032$ ).

The results of the tests using other species of Orconectes as recipient crayfish yielded rather surprising results. For both $O$. propinquus (Table 5) and $O$. rusticus (Table 6), there was no difference in the postures shown by crayfish when water from disturbed and undisturbed crayfish was introduced. For both species, the recipient crayfish's postures indicated they were well adjusted (undisturbed) to the laboratory situation. Their lack of response to water from different sources was not all because the test individuals were too active in the laboratory situation. The one marginally significant result in all the comparisons (neutral postures for the $O$. propinquus $-O$. propinquus tests) was in the opposite direction to that expected. In would appear that individuals of these two species do not respond to disturbance chemicals given off by conspecific individuals.

Table 5. Average ( \pm SD) Number of Seconds during 8-min Observation Spent by $O$. propinquus with One or More Parts in Neutral and Full Down Posture WHEN WATER FROM VARIOUS SOURCES (SAMPLE SIZES IN PARENTHESES) WAS INTRODUCED ${ }^{a}$

\begin{tabular}{lcccccccc}
\hline & \multicolumn{3}{c}{ Neutral postures } & & \multicolumn{3}{c}{ Full down posture } \\
\cline { 2 - 3 } \multicolumn{1}{c}{ Source water } & Undisturbed & Disturbed & $P$ & & Undisturbed & Disturbed & $P$ \\
\hline O. propinquus $(18)$ & $199( \pm 182)$ & $101( \pm 128)$ & 0.042 & & $197( \pm 210)$ & $183( \pm 186)$ & 0.696 \\
O. virilis (18) & $155( \pm 162)$ & $206( \pm 162)$ & 0.257 & & $203( \pm 199)$ & $125( \pm 166)$ & 0.110
\end{tabular}

${ }^{a} P$ values associated with paired $t$ tests comparing responses shown to water from undisturbed and disturbed source animals.

Table 6. Average $( \pm$ SD) Number of Seconds during 8-min Observation Spent by $O$. rusticus with One or More Parts in Neutral and Full Down Posture WHEN WATER FROM CONSPECIFIC INDIVIDUALS WAS INTRODUCED ${ }^{a}$

\begin{tabular}{lcc}
\hline & Neutral postures & Full down posture \\
\hline Undisturbed & $53( \pm 68)$ & $390( \pm 143)$ \\
Disturbed & $77( \pm 94)$ & $361( \pm 155)$ \\
& $P=0.364$ & $P=0.459$ \\
\hline
\end{tabular}

\footnotetext{
${ }^{a} P$ values associated with paired $t$ tests comparing responses to water from undisturbed and dis-
} turbed source animals. Sample size was 20 . 


\section{DISCUSSION}

Since environmental disturbances induce biochemical changes in a variety of animals (Kerambrun and Guérin, 1984) and disturbances can affect a wide variety of animals in local communities, we might expect obtaining information about disturbances by chemical means to be widespread. The responses of crayfish to water occupied by disturbed (more active) and undisturbed (less active) aquatic animals point to a very general channel of chemical communication in a very specific case. Individuals of Orconectes virilis respond to a chemical or chemicals given off by a wide variety of animals when the latter are disturbed (induced to a high level of activity). At the same time, other species of crayfish show no such response. The latter is particularily surprising since both $O$. propinquus and $O$. rusticus give off a chemical to which individuals of $O$. virilis respond (Hazlett, 1985a). In fact, the easily disturbed nature of $O$. rusticus and the clear responsiveness of $O$. virilis to disturbed $O$. rusticus led me to use $O$. rusticus as the preferred source species for the chemical(s) (Hazlett, 1985a, this report). $O$. propinquus does distinguish water from conspecifics vs. $O$. virilus (Tierney and Dunham, 1982) but shows no sign of distinguishing between disturbed and undisturbed animals of either species.

There are no obvious differences in the ecology of the three species of crayfish tested that correlate with the pattern of responsiveness. All three species can be found in the same stream (Capelli and Capelli, 1980), although there is evidence for both resource partitioning between $O$. virilis and $O$. propinquus (Quinn and Janssen, 1989; Rabeni, 1985) and species displacements by $O$. rusticus (Capelli and Munjal, 1982; Capelli and Magnuson, 1983). Both of these processes point toward similarities in resource utilization by the three species. $O$. virilis does have a more complex mating system (Ameyaw-Akumfi and Hazlett, 1975; Hazlett, 1983) than either O. propinquus (Ameyaw-Akumf, 1976) or O. rusticus (Berrill and Arsenault, 1982), but this only indicated a generally higher level of behavioral complexity in $O$. virilis and does not offer ecological/evolutionary causal mechanisms. The lack of responsiveness in crayfish known to produce a chemical message does point towards a communication system that has been shaped only on the recipient side.

The wide phyletic diversity of aquatic species that can act as sources of a chemical signal and the suggestion that a waste product (ammonia) may be a part of the chemical signal also suggest a system that has been modified only in the receiver. Other crustacea can detect ammonia at concentrations similar to that used in this study (Derby and Atema, 1982a,b), but it appears that a behavioral response to such detection does not occur in $O$. rusticus and $O$. propinquus, while it does occur in $O$. virilis.

The results of the series of tests on the source of the chemical signal in 
crayfish very strongly suggest there are chemicals released from the green gland of crayfish as well as ammonia from the gills that contribute to the response by recipient $O$. virilis. A chemical signal generated from two sites within a sender is somewhat unusual, although this has been reported in other aquatic organisms (Rittschof and Brown, 1986), and multiple sites are not unknown (Heschl, 1989).

All of the above brings up an important semantic question. When at least a portion of the response to a chemical signal is to a very general waste product, should it be called a pheromone? Or is the term semiochemical more appropriate? In their original definition of pheromone, Karlson and Lusher (1959) emphasized intraspecific chemical communication by secreted substances but allowed that "overlap" between closely related species could occur. Katz and Shorey (1979) also stressed the intraspecific nature of pheromonal action. When it appeared that other species in the genus Orconectes gave off the chemical(s) (Hazlett, 1985b), the use of the term pheromone was not overextended. However, when at least a portion of the response by individuals of $O$. virilis appears to be elicited by a waste product common to almost all aquatic animals, the use of the term pheromone seems inappropriate. The green-gland-derived portion of the response may fit the broad definition of pheromone, but the overall response may best be described as a semiochemical (Norlund and Lewis, 1976) response, since it can involve both intraspecific and interspecific communication.

Whatever this system is called, it appears that it has three interesting features. As is true with other "alarm" systems (Lawrence and Smith, 1989), there appears to be a marked delay between probable detection of the chemical(s) and initiation of a behavioral response. At the ecological level this makes sense in that short spurts of "disturbance" chemicals are probably not indicative to a receiver of a general, potentially dangerous situation while a prolonged chemical message may signal such conditions in the environment. This leads to the second behavioral feature of the response, which is its long duration. Once on alert (to potential changes of an unspecified nature), it would be to the animal's advantage to be wary for some time. The increased level of responsiveness to various types of stimulus input (the third feature of the system) further suggests that the function of the response to the disturbance semiochemical in $O$. virilis is to be ready to react to any of a variety of situations. Whether this type of response by individuals of $O$. virilis is a result of past selection or the result of individual experience can only be answered by studies of the ontogeny of the system (Rittschof et al., 1984).

Acknowledgments-I wish to thank Carolyn Manley for her assistance in all phases of the experiments in the 1988 series. I also wish to thank Dr. Rebbeca Glover for providing assistance with the ammonia determinations and Dr. Dan Rittschof for his comments on the manuscript. 


\section{REFERENCES}

AmeYaw-Akumfi, C.E. 1976. Some aspects of the breeding biology of crayfish. PhD thesis. University of Michigan, Ann Arbor, Michigan.

AMEYAW-AKumFi, C.E., and Hazlett, B.A. 1975. Sex recognition in the crayfish Procambarus clarkii. Science 190:1225-1226.

BERRILL, M., and ARSENAULt, M. 1982. Spring breeding of a northern temperate crayfish, Orconectes rusticus. Can. J. Zool. 60:2641-2645.

CAPELli, G.M., and CAPELLI, J.F. 1980. Hybridization between crayfish of the genus Orconectes: Morphological evidence (Decapoda, Cambaridae). Crustaceana 39:121-132.

CAPELLI, G.M., and MAGNUSON, J.J. 1983. Morphoedaphic and biogeographic analysis of crayfish distribution in northern Wisconsin. J. Crust. Biol. 2:486-492.

CAPELLI, G.M., and MUNJAL, B.J. 1982. Aggressive interactions and resource competition in relation to species displacement among crayfish of the genus Orconectes. J. Crust. Biol. 2:486492.

DERBY, C.D., and ATEMA, J. 1982a. Chemosensitivity of walking legs of the lobster Homarus americanus neurophysiological response spectrum and thresholds. J. Exp. Biol. 98:303-315.

DERBY, C.D., and ATEMA, J. 1982b. Narrow-spectrum chemoreceptor cells in the walking legs of the lobster Homarus americanus: Taste specialists. J. Comp. Physiol. 146:181-189.

GleEson, R.A. 1980. Pheromone communication in the reproductive behavior of the blue crab, Callinectes sapidus. Mar. Behav. Physiol. 7:119-134.

HAZLETT, B.A. 1983. Parental behavior in Decapod Crustacea, pp. 171-193, in S. Rebach and D. Dunham (eds.). Studies in Adaptation, The Behavior of Higher Crustacea. John Wiley \& Sons, New York.

HAZleTt, B.A. 1985a. Chemical detection of sex and status in Orconectes virilis. J. Chem. Ecol. 11:181-189.

HAZlett, B.A. 1985b. Disturbance pheromones in the crayfish Orconectes virilis. J. Chem. Ecol. 11:1695-1711.

HAZLETT, B.A. 1989. Additional sources of disturbance pheromone affecting the crayfish. Orconectes virilis. J. Chem. Ecol. 15:381-385.

HESCHL, A. 1989. Integration of "innate" and "learned" components within the IRME for mussel recognition in the European bitterling Rhodeus amarus (Bloch). Ethology 81:193-208.

KATZ, R.A., and Shorey, H.H. 1979. In defense of the term "pheromone." J. Chem. Ecol. 5:199-301.

KARLSON, P., and LuSHER, M. 1959. "Pheromone": A new term for a class of biologically active substances. Nature 183:55-56.

KeRAMBrUN, P., and GuéRIN, J. 1984. L'électrophorèse dans l'étude des stress chez les invertébrés marins. Bull. Soc. Zool. Fr. 109:333-341.

LAWRENCE, B.J., and SMITH, R.J.F. 1989. Behavioral response of solitary fathead minnows, Pimephales promelas, to alarm substance. J. Chem. Ecol. 15:209-219.

NoRlund, D.A., and LewIS, W.J. 1976. Terminology of chemical releasing stimuli in intraspecific and interspecific interactions. J. Chem. Ecol. 2:211-220.

Petranka, J.W., Kats, L.B., and Sih, A. 1987. Predator-prey interactions among fish and larval amphibians; use of chemical cues to detect predatory fish. Anim. Behav. 35:420-425.

QUINN, J.P., and JANSSEN, J. 1989. Crayfish competition in southwestern Lake Michigan: A predator mediated bottleneck. J. Freshw. Ecol. 5:75-85.

RABENI, C.F. 1985. Resource partitioning by stream-dwelling crayfish: The influence of body size. Am. Midl. Nat. 113:20-29. 
RitTsChOF, D., and BROWN, A.B. 1986. Modification of predatory snail chemotaxis by substances in bivalve prey odors. Malacologia 27:281-290.

RitTSChoF, D., KeibER, D., and MERrill, C.L. 1984. Modification of response thesholds of newly hatched snails by odor exposure during development. Chem. Senses 9:181-192.

Rose, R.D. 1986. Chemical detection of "self" and conspecifics by crayfish. J. Chem. Ecol. 12:271-276.

STEMBERGER, R.S., and GiLBERT, J.J. 1987. Multiple-species induction of morphological defenses in the rotifer Keratella testudo. Ecology 68:370-378.

Tierney, A.J., and Dunham, D.W. 1982. Chemical communication in the reproductive isolation of the crayfishes Orconectes propinquus and Orconectes virilis (Decapoda, Cambaridae). $J$. Crust. Biol. 2:544-548. 